\title{
Rhodnius paraensis espécie nova do Estado do Pará, Brasil (Hemiptera, Reduviidae, Iriatominae)(*)
}

\author{
italo A. Sherlock (**) \\ Neide Guitton ( $*$ ) \\ Michael Miles $(\stackrel{m *}{*})$
}

\begin{abstract}
Resumo
Os Autores descrevem o Rhodnius paraensis nova espécie com base em 18 exemplares coletados nos arredores de Belém, Estado do Pará, Brasil. A nova espécie é facilmente diferenciada das outras espécies pelo tamanho e por possuir marcaçōes aneiares cialas nas patas e ter o processo do pigóforo semibifurcado.
\end{abstract}

Descrevemos no presente trabalho uma nova espécie de triatomineo pertencente ao gênero Fhodnius, cujos exemplares foram coletados por um dos Autores em 1975, nos arredores da cidade de Belém, Estado do Pará, em ninho de roedor. O material que recebemos, tratava-se de 1 adulto morto fêmea e 18 ninfas vivas em diversos estágios, as quais mantivemos vivas em laboratório. Essas ninfas foram alimentadas semanalmente em galos e com bastante dificuldade algumas evoluíram até a fase de adultos, num periodo de 12 meses. Foram assim obtidos 6 exemplares fêmeas e 1 exemplar macho desse triatomíneo.

A espécie havia sido inicialmente identificada como Rhodnius domesticus Neiva \& Pinto, 1923 por ser a esta muito semelhante. Um exame mais cuidadoso demonstrou entretanto que se tratava de uma nova espécie para a qual propusemos o nome de Rhodnius paraensis sp. n., em homenagem ao Estado do Pará.

Um resumo da descrição dessa espécie já foi apresentado nos Congressos XII da Sociedade Brasileira de Medicina Tropical e I Congresso da Sociedade Brasileira de Parasitologia, realizados em Belém em 1976, onde o nome de M. Miles por um lápso foi omitido como co-autor da espécie e aqui corrigimos o erro.

(') - Trabalho do Núcleo de Pesquisas da Bahia - FIOCRUZ.

(“") - Núcleo de Pesquisas da Bahia (FIOCRUZ), Salvador. Bahia.

(**) - London School of Higiene and Tropical Medicine.
O material de que dispusemos, a fim de ser preservado, não foi dissecado e examinado para $T$. cruzi. A sua susceptibilidade à infecção experimental pelo $T$. cruzi também não foi verificada. Os exemplares parátipos seräo depositados na coleção do Instituto Oswaldo Cruz do Rio de Janeiro e no Museu Paraense Emilio Goeldi.

DESCRIÇÃo

Rhodnius paraensis $\mathrm{sp} . \mathrm{n}$. (Fig. 1 a 11)

Comprimento - Fêmea $12 \mathrm{~mm}$; macho $11 \mathrm{~mm}$.

Largura máxima ao nível do pronoto $3 \mathrm{~mm}$.

Inseto pequeno, de colorido geral castanho escuro, com marcas enegrecidas e claras em várias regiões do corpo, tendo o tegumento granulações e rugosidades microscópicas que dão reflexos brilhantes (Fig. 1).

Cabeça relativamente curta, quase de comprimento ou levemente maior que do pronoto, tendo $2 \mathrm{~mm}$ de comprimento e $1 \mathrm{~mm}$ de largura ao nivel dos olhos. As genas escurecidas ultrapassam ligeiramente o tylus. Olhos têm diâmetro horizontal menor que o vertical, na face ventral da cabeça são aproximados e na dorsal afastados. Distância interocular dorsal maior que a largura de um só olho. Ocelos laterais, mais afastados entre si do que os olhos, alongados no sentido longitudinal $e$ in. crustados em discretas saliências ocelares. Calosidade lateral pós-ocular nítida. 
Antenas com o primeiro segmento negro. não atingindo o ápice da cabeça; o $2 .^{\circ}$ segmento também negro, mais estreito e mais longo, cerca de 4 vezes o comprimento do $1 .^{\circ}$; o $3 .^{\circ}$ mais delgado, com a metade proximal de cor negra e metade apical clara, de comprimento ligeiramente menor que o $2 .^{\circ}$; o $4 .^{\circ}$ é delgado, claro e menor que o $3 .^{\circ}$.

A região anteocular tem cerca de 2 vezes o comprimento da pós-ocular.

A cabeça tem partes laterais enegrecidas e parte dorsal castanho claro, com uma faixa

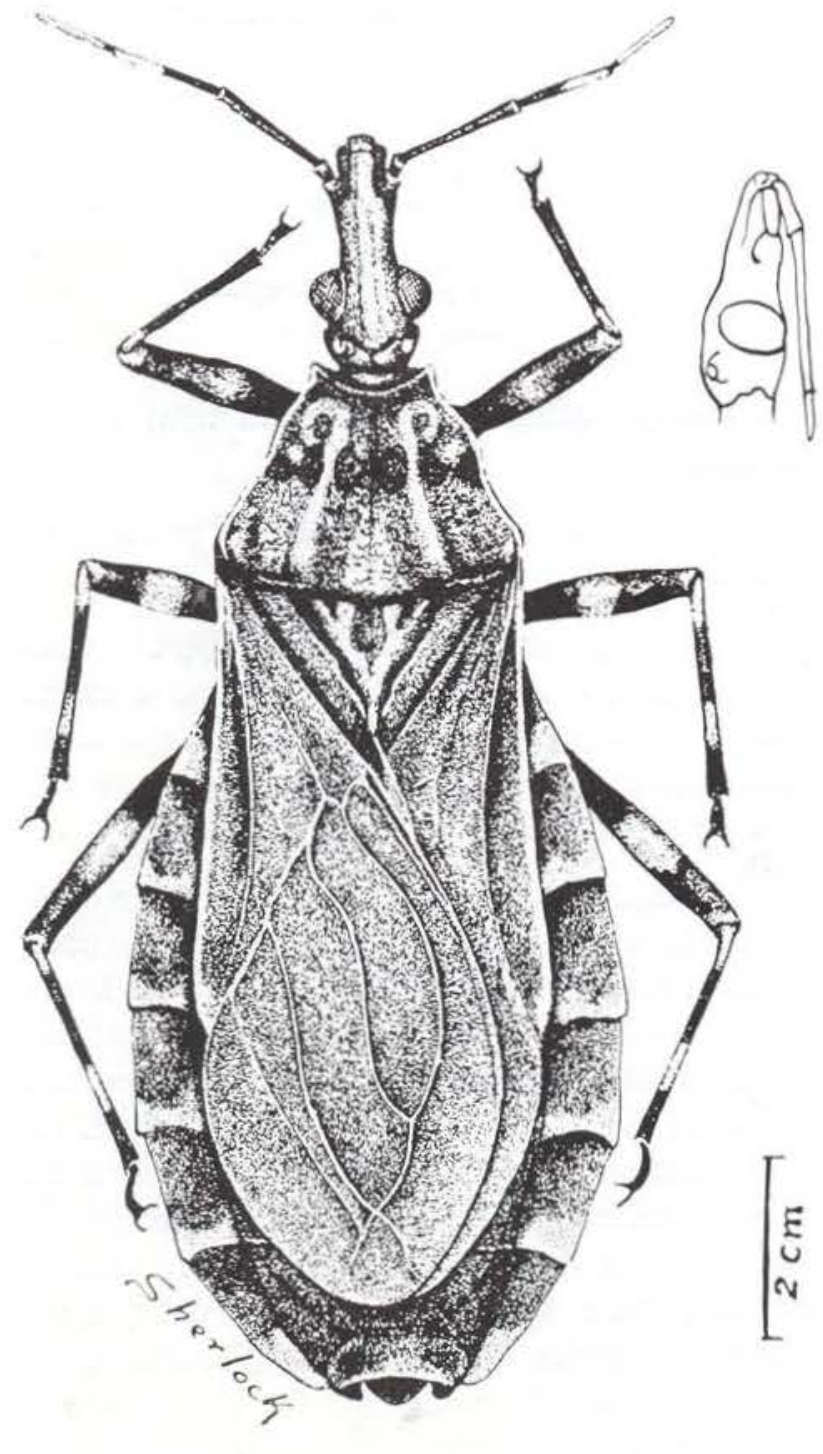

Fig. $1-$ Rhodnius paraensis sp. n. aspecto geral da fêmea. longitudinal mediana mais clara, limitada de cada lado por estreitas linhas enegrecidas. $\mathrm{Na}$ região pós-ocular, partindo de cada olho, existe uma faixa enegrecida que atinge o pescoço.

$\mathrm{O}$ rostro achatado dorsalmente é revestido de cerdas curtas, pouco abundantes. Quando retraído, o $1 .^{\circ}$ segmento termina ao nível da articulação das antenas com os tubérculos anteniferos; o $2 .^{\circ}$ segmento é cerca de 3 vezes mais longo que o $1 .^{\circ}$ e atinge o bordo posterior da cabeça; o $3 .^{\circ}$ segmento é aproximadamente do comprimento do $10^{\circ}$ e possui alguns pêlos e de cor castanha.

Pronoto com o lobo posterior delimitado do anterior por um sulco transversal adiante do meio do comprimento total. O lobo anterior é granuloso e apresenta placas arredondadas negras e glabras ao nível do sulco, as quais são separadas pelas carenas longitudinais em três grupos de 2 placas. As carenas longitudinais, de cor castanho-clara, se prolongam, no cclarinho ao bordo posterior do pronoto. No lóbulo anterior, fazem um desenho em semicircunferência, dando o aspecto de duas interrogações em posições opostas.

No lobo posterior, existe uma faixa mediana de forma piramidal que se alarga para o bordo posterior do pronoto. As bordas laterais são salientes e de cor castanho-claro.

As pleuras são escuras, sendo a parte superior da propleura clara.

Esterno sem características dignas de notar.

Escutelo com uma escavação central negra circundada por saliências claras, assim como seu ápice.

Patas relativamente curtas e escuras, com pilosidade discreta dourada; trocânteres e articulações claras. Fêmures fortes com um anel mediano castanho-claro. Tíbias anteriores e medianas com anel castanho-claro basal e tíbias posteriores com 2 anéis claros, um basal e outro submediano. Fossetas esponjosas pequenas, no ápice das tíbias anteriores e medianas.

Hemiélitros curtos, deixando boa parte da porção terminal do abdômen descoberta, de cor 

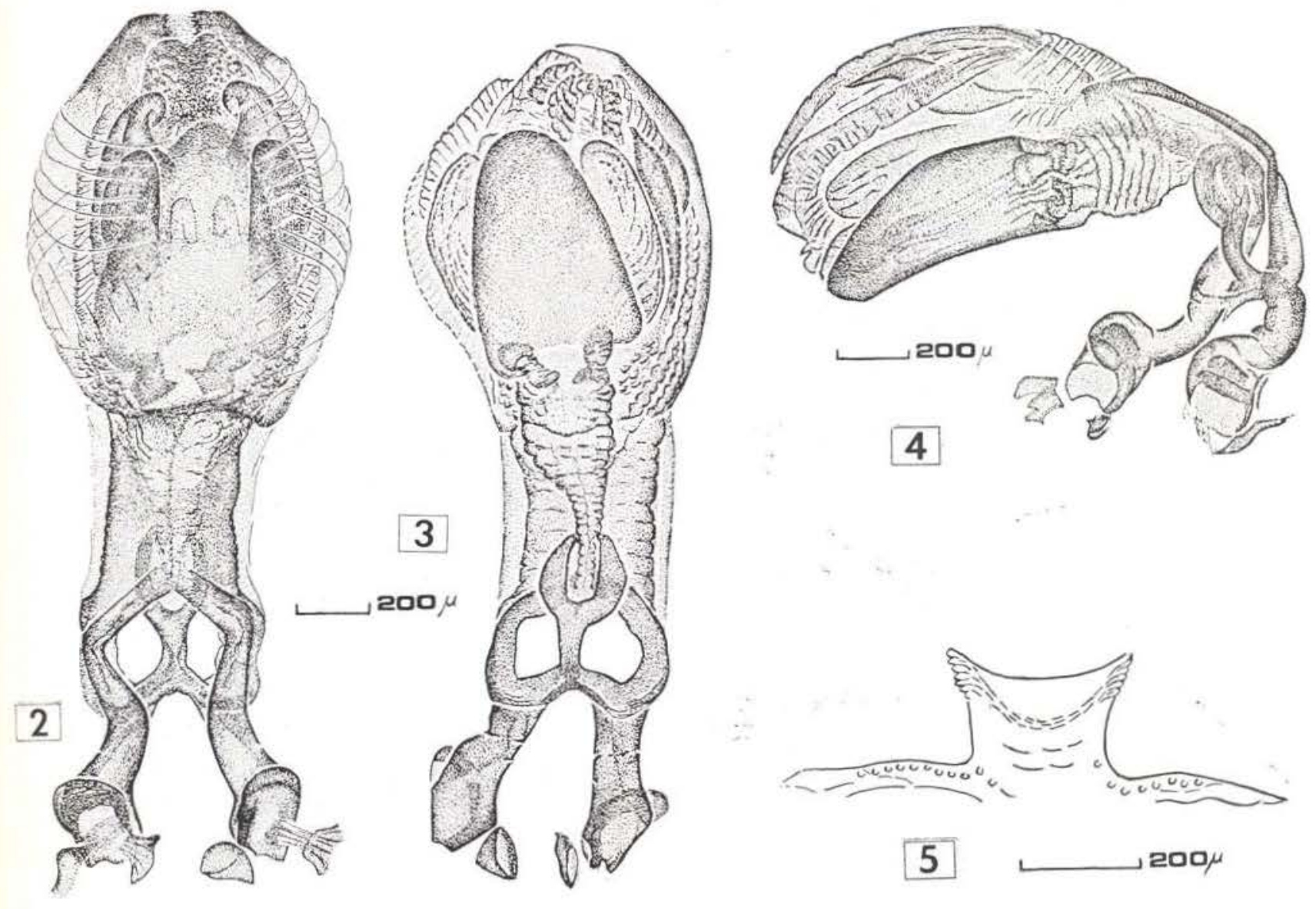

$52200 \mu$

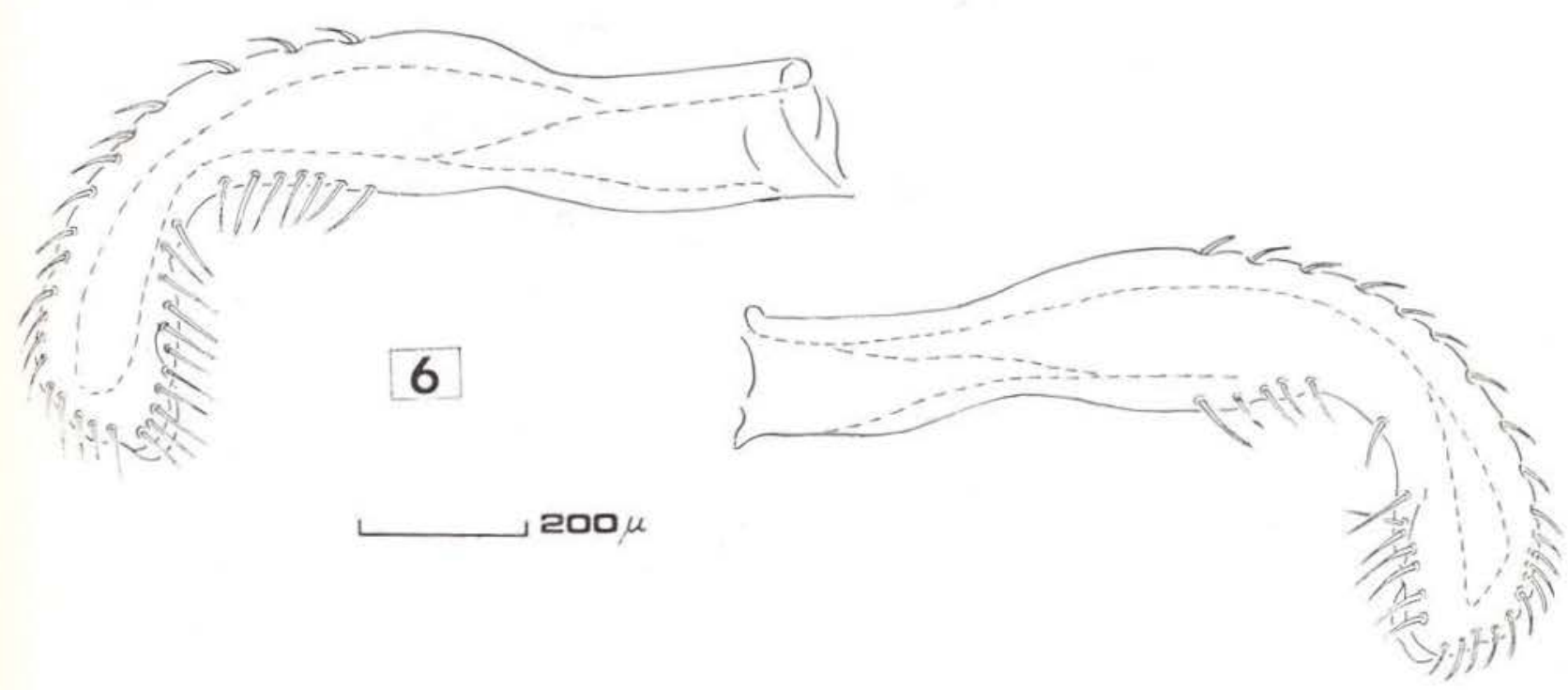

Rhodnius paraensis sp. n., genitália do macho - Fig. 2: phallus, vista dorsal; Fig. 3: phallus, vista ventral; Fig. 4: phallus, de perfil; Fig. 5: processo mediano do pigóforo; Fig. 6: parâmeros. 
escura, tendo os oordos o as nervuras discretamente mais claros do que as células.

Conexivo dorsal largo, de cor escura em quase todos os $2 / 3$ basais de cada segmento, tendo apenas a parte distal de cada segmento mais clara, formando pontas penetrantes na área negra.

Conexivo ventral estreito e bem diferen ciado por um sulco na parte ventral do abdômen e pela coloração clara dos segmentos correspondentes. Também como o dorsal a cor escura toma cerca dos $2 / 3$ basais de cada segmento do conexivo.

Abdômen com coloração mesclada de castanho-clara e escura, diferenciando-se bem os seus bordos e os estígmas respiratórios mais claros. Na parte mediana ventral, existen áreas glabras arredondadas.

Genitálias conforme as figuras. Tem-se a salientar o processo mediano do pigóforo do macho que é quase bifurcado e também a forma do falosoma que é mais alongado que o $R$. domesticus Neiva \& Pinto, 1923 (Figs. 2 a 11).

\section{DIAGNOSE DIFERENCIAL}

A espécie que mais se aproxima de $R$. paraensis sp. n., e que também tem a cabeça proporcionalmente curta com relação ao pronoto, é $R$. domesticus Neiva \& Pinto, 1923, que, entretanto, poderá ser facilmente diferenciada, como a seguir demonstramos. O R. amazonicus Almeida, Santos \& Spocina, 1973 é facilmente diferenciado, pois, além de possuir marcações anelares escuras nas tíbias, é também diferente da nova espécie devido a vários outros caracteres.

Os principais caracteres que distinguem כ R. paraensis das outras espécies são: o tamanho de apenas $12 \mathrm{~mm}$, a marcação anelar clara dos fémures e tíbias e o processo do pigóforo que em quase todas as espécies é pontiagudo. sendo nesta nova espécie meio bifurcado e por isso é intermediário entre o de $R$. pictipes Stal, 1872, que é bifurcado, e $R$. domesticus que é quadrangular. Outra diferença é que no R. pa. raensis sp. n., o falosoma é mais alongado que em $R$. domesticus.

MATERIAL ESTUDADo - Os exemplares tipos estudados, em número de dez, todos eles coletados em ninhos de Didelphis marsupialis localizados em árvores em Utinga, Belém, Estado do Pará. Esses exemplares tipos foram depositados nas seguintes instituições: 1 ô holótipo 1 \& parátipo, no Instituto Oswaldo Crliz; 2 \& parátipos, no Museu Emílio Goeldi; 1 ô e 2 ? parátipos e 3 ninfas, que estão ainda sendo mantidas vivas e que serão depositadas no Núcleo de Pesquisas da Bahia da FIOCRUZ.

\section{SUMMARY}

Rhodnius paraensis n. sp. is described based on 18 especimens collected near the city of Belém, State of Pará, Brazil.

This species is easily separated from the other species of Rhodnius because its small size, the existence of light spot rings on its legs and the shape of the pigophore. 

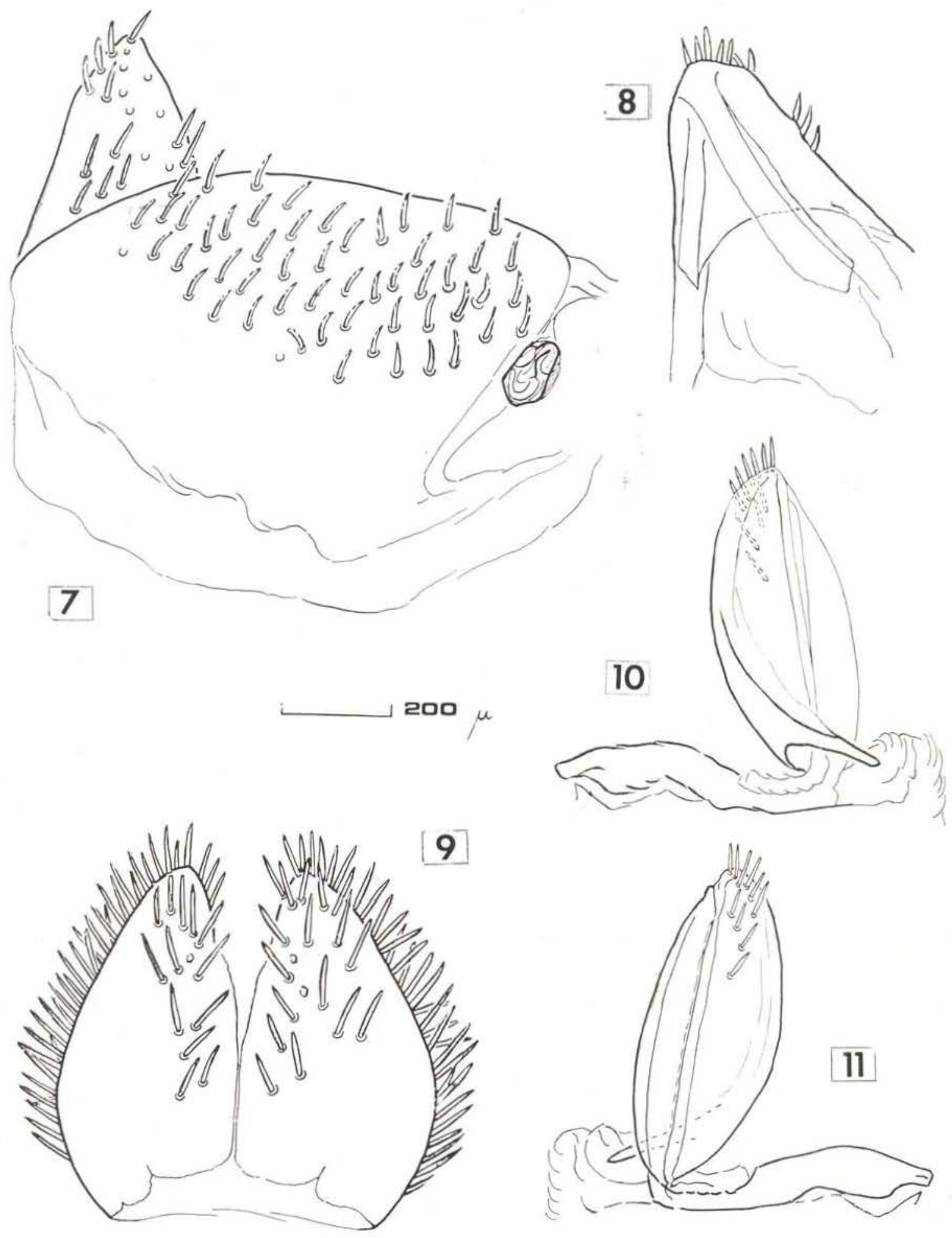

Rhodnius paraensis sp. n., genitália da fêmea - Fig. 7: gonocóxitos e gonapófise do 8. segmento; Fig. 8: gonapófise do $8 .^{\circ}$ segmento; Fig. 9: gonocóxitos do 9.० segmento; Figs. 10 e 11: gonapófises do $9 .^{\circ}$ segmento. 